\title{
O hilotismo e a revolução social em Esparta
}

\author{
MARIA APARECIDA DE OLIVEIRA SILVA \\ Departamento de História \\ Faculdade de Filosofia, Letras e Ciências Humanas \\ Universidade de São Paulo
}

\begin{abstract}
RESUMO: A conquista da Messênia representou, por dois séculos, a resolução dos problemas agrário, político e econômico em Esparta. No entanto, as contradições internas dessa sociedade contribuíram para a quebra da hegemonia dos cidadãos no exército espartano. Em virtude da oligantropia, a participação hilota no exército de Esparta torna-se imperativa, apesar de representar uma rachadura no sistema. O objetivo deste artigo é o de discutir a revolução social provocada em Esparta com a inclusão dessa categoria em seu corpo militar.
\end{abstract}

PALAVRAS-CHAVE: Esparta; hilotas; oligantropia.

A hegemonia alcançada após a vitória na guerra do Peloponeso não foi suficiente para manter a cidade de Esparta em evidência durante o século IV a.C. Como seria possível uma cidade derrotar sua maior rival e não conseguir sustentar a sua própria supremacia por muitos anos? A dificuldade em se responder a essa questão sobre a ruína do regime espartano tem despertado sobremaneira a curiosidade dos helenistas. Assim, desde a antigüidade, existe a elaboração de inúmeras teorias a respeito das causas da perda de seu poderio na Grécia. Os antigos atribuíam a um legislador mítico conhecido como Licurgo a instituição de leis que garantiram a Esparta a formação de um exército superior a qualquer outro dentro do Mediterrâneo antigo. No bojo dessa discussão surgem duas correntes de pensamento: a primeira, de origem filolacônica, que vê no abandono das leis licúrgicas o motivo da decadência do sistema; e a segunda corrente, filoateniense, que atribui as causas do declínio de Esparta às falhas na elaboração das leis. Com isso, torna-se perceptível aos olhos de um observador que, na antigüidade, a preocupação em discutir a decadência dos sistemas políades do mundo mediterrâneo apresenta-se como um meio de construir um modelo citadino capaz de resistir à temporalidade dos acontecimentos.

A partir destas questões, o objetivo deste artigo é o de estabelecer uma melhor compreensão do papel exercido pelos hilotas em Esparta no momento de sua inserção no exército espartano. As transformações sociais oriundas desse movimento representam uma verdadeira ruptura no sistema político espartano; dessa forma, a participação hilota alterou a harmonia existente entre as categorias sociais abrindo espaço para o aparecimento das contradições internas de um sistema pautado pela desigualdade social de seus integrantes.

A partir da leitura da produção historiográfica especializada, nascida no século passado e influenciada pelo positivismo histórico, é possível notar que esta apenas reprodu- 
ziu a discussão dos antigos sobre as causas da falência do sistema citadino. Somente nesse século surge a preocupação em se discutir as causas da decadência do regime espartano, cuja análise centra-se nas contradições inerentes a um sistema que alimenta a desigualdade social entre os seus participantes. A bibliografia, principalmente da segunda metade desse século, volta-se para o estudo das classes inferiores na tentativa de visualizar os conflitos internos que interferiram na organização social e política de Esparta tentando distanciar-se da visão aristocrática das fontes escritas.

O debate em torno das ações sociais realizadas pelas diferentes camadas que compõem a organização do sistema espartano abre espaço para a discussão sobre a sua efetiva participação nas decisões citadinas. Em artigo ${ }^{1}$ publicado no final dos anos sessenta sobre a cidade de Esparta, Moses Finley, então professor da Universidade de Wisconsin, identifica alguns elementos, a saber, o exército, a corrupção do poder, a tensão em torno do poder, a excessiva mobilidade social, o contato com o exterior e finalmente as mulheres, como os elementos catalisadores dos conflitos sociais em Esparta ${ }^{2}$. Em sua reflexão, o autor permite a visualização de uma sociedade bem distante da mirage $e^{3}$ difundida ao longo dos séculos.

No entanto, os elementos de tensão e anomia, apontados por Finley, podem ser atribuídos a um tipo de relação extremamente conflituosa: o hilotismo ${ }^{4}$. O exército realmente teria sido a causa da derrocada espartana; porém, não o foi em virtude do enfraquecimento de suas forças ou de um suposto abandono do militarismo espartano. A oligantropia, "a falta de cidadãos" durante as batalhas ocorridas na guerra do Peloponeso, impeliu os comandantes militares (polemarcas) a convocarem muitos indivíduos não-cidadãos para o desempenho de várias funções dentro do corpo militar. Ora, o exército espartano, na verdade, era conhecido como lacedemônio ${ }^{5}$, ou seja, composto até então de cidadãos espartanos e periecos, sendo os hilotas os únicos excluídos.

O segundo aspecto negativo de Esparta, apontado por Finley, remete-nos à excessiva mobilidade social. Todavia, o autor desconsidera o caráter agrário da sociedade espartana que, ao contrário do ocorrido em Atenas, permaneceu essencialmente agrária, pautada pelo trabalho servil do hilota. Nesse sentido, a participação no exército abre a possibilidade de obtenção da liberdade, bem como da acumulação de alguma riqueza para o hilota. A terra perde assim o seu atrativo, pois, se no período arcaico a segurança de um abrigo nas terras do Estado garantia alguma tranquiilidade ao hilota para constituir sua família, no final do período clássico, com as inúmeras guerras, a cidade não detém mais o controle total de seu território. As invasões da periferia da cidade provocam perdas tanto para os hilotas como para a aristocracia agrária, que vêem a sua fonte de renda totalmente destruída pelos sucessivos ataques de seus vizinhos. Esses acontecimentos despertam a ira da classe aristocrática dos senadores e éforos, o que os faz entrar em conflito com os reis ${ }^{6}$, os maiores incentivadores de campanhas militares.

A entrada abrupta de riquezas em Esparta, termina desestruturando a base agrária de sua sociedade no período clássico, visto que antes a troca de favores se dava com a concessão de terras. No século IV a. C., a falta de trabalho braçal nas propriedades agrárias e a redução do número de cidadãos, somados à concentração desmedida de terras, restringe a um grupo bem seleto a posse da terra. Dessa forma, os metais preciosos assumem maior importância no momento da realização de acordos, embora o princípio da posse da terra continuasse a determinar diferenças entre cidadãos e não-cidadãos.

A aristocracia, vitoriosa na guerra do Peloponeso, há muito abandonara as suas características militares do período arcaico; assim a acumulação de riquezas oriundas dos despojos de guerra acentua a distância econômica entre os cidadãos. Os mais empobreci- 
dos, os chamados hypomeiones, são proibidos de participar dos banquetes públicos conhecidos como syssitia. Esses repastos públicos serviam como demonstração da inferioridade desses cidadãos desprovidos de opulência e luxo quando comparados aos aristocratas, comedores de butim. Outra fonte de captação dessa imensa mão-de-obra é o trabalho mercenário ${ }^{7}$ em outros exércitos, nos quais muitos dos cidadãos inferiorizados em Esparta terminam por ocupar um cargo de chefia em uma guarnição militar da cidade que os contratou.

No final do século IV a. C., e principalmente no século III a. C, o exército espartano transforma-se em uma fonte de renda. As sucessivas guerras resultam em recursos financeiros não somente para os reis e seus aliados (hilotas e os hypomeiones), como também para os aristocratas, donos de grande parte da terras espartanas. Mas apesar da posse de terras, estes últimos não acumulavam metais preciosos, daí a garantia de uma negociação entre as partes estava no poder de decisão no concernente aos assuntos da cidade, uma vez que os aristocratas detinham em suas mãos a ocupação de cargos políticos.

$\mathrm{Na}$ oposição criada entre a elite detentora do poder, representada no embate entre os reis espartanos e a aristocracia administrativa, a figura do hilota aparece no centro da contenda. O hilota, ao participar do exército, poderia almejar a liberdade por ato de bravura e/ou amealhar algum montante em peças de metais preciosos. Esse fato termina por propiciar o desenvolvimento de três problemas graves nas relações sociais em Esparta. O primeiro foco de tensão surge ao se colocar lado a lado duas classes distintas lutando pelo mesmo objetivo, pois para a classe dos cidadãos o exército significava uma demonstração de honra reservada apenas a eles ${ }^{8}$. O segundo nasce da ascensão econômica de indivíduos libertos que influenciam os cidadãos em suas decisões. E o último ponto refere à oposição dos aristocratas aos reis, pois consideravam excessiva a aproximação dos monarcas das classes inferiores, julgando que os reis não eram dignos do gerenciamento das questões públicas.

A excessiva mobilidade social identificada por Finley não teria sido possível portanto até a inserção do hilota no exército, quando alguns servos espartanos conquistaram riquezas e liberdade. No século III a. C. o rei Cleômenes cobra uma quantia elevada de dois mil hilotas em troca da liberdade, provavelmente daqueles que não encontraram uma oportunidade de realizar um ato de bravura para alcançar a alforria por mérito; esses indivíduos, no entanto, acumularam riqueza suficiente para comprá-la. É provável que os hilotas libertos pelo sistema de compra da alforria detivessem em suas mãos grandes quantidades de metais preciosos em forma de taças, jóias e de moedas colhidas em regiões onde se adotava a cunhagem em ouro e prata. De posse dessa riqueza, essa massa de hilotas libertos alia-se aos reis para patrocinar empresas militares em oposição à relutância dos éforos e senadores partidários do encerramento das ações militares.

Com relação à experiência no exterior, pode-se inferir que esta somente se teria dado com o relaxamento de um regime austero, o qual separava claramente a classe dos cidadãos e a dos não-cidadãos. Enquanto a sociedade espartana, no período arcaico, esteve sustentada apenas pelo cultivo da terra, o exército cumpria uma função de polícia interna, cujo objetivo principal era o de conter as revoltas dos hilotas. Outro papel importante desempenhado pelo exército dizia respeito à manutenção das fronteiras conquistadas. No período clássico, por sua vez, essa estrutura começa a dar mostras de suas limitações que, na tentativa de sobrevivência e mesmo contrariando os preceitos antigos, incorpora a importante força de defesa oferecida pelos hilotas. Esse sistema, todavia, deve responder com premiações que estimulem o retorno de seus soldados, pois nada impediria uma fuga em massa ou a revolta desse contingente armado se não houvesse uma troca entre as partes. 
Sobre as mulheres representarem uma "rachadura" no sistema espartano, Finley não desenvolve uma linha de pensamento a respeito do assunto, apenas cita Platão e Aristóteles. O debate sobre a participação feminina na sociedade espartana é perceptível somente nos escritos aristotélicos; o que vemos em Platão, tanto na República quanto nas Leis, é a construção de um sistema ideal, sem qualquer relação com a realidade de Esparta no tocante às ações femininas. Quanto às informações de Aristóteles sobre a mulher espartana, elas parecem exageradas em relação ao grau de liberdade feminina na cidade. É impreciso o fato de as mulheres possuírem terras em Esparta. Além do testemunho aristotélico, temos as informações de Plutarco sobre a lei de Epitadeu, que concedia às mulheres o direito à herança.

No caso da mulher espartana herdar realmente as terras de seus homens mortos, é preciso observar que a mulher na Grécia era reconhecidamente incapaz de tomar decisões próprias, tendo sempre ao seu lado um kyrios, que em grego significa "cabeça", para lhe determinar as tarefas. Os registros antigos não relatam uma ação isolada das mulheres espartanas, elas sempre têm ao seu lado o marido, um filho ou um irmão, responsáveis naturais pelas mulheres de uma família naquela sociedade. No entanto, tal fato não exclui a ação de um grupo de mulheres que, de alguma forma, atinge seus objetivos por meio da ação política dos homens, mas é preciso ter em vista as limitações desses atos.

Em síntese, pode-se dizer que a reflexão de Finley a respeito do funcionamento do sistema social espartano desqualifica a força do hilotismo dentro de sua organização social, principalmente porque seus argumentos sobre os elementos que contribuíram para o desmantelamento da cidade resumem-se a uma análise superficial das relações sociais em Esparta. Caso Finley se tivesse voltado especificamente para as ações sociais dos hilotas, certamente observaria que os pontos que identifica como perturbadores da ordem interna resumem-se, na verdade, a apenas um, ou seja, toda argumentação apenas evidencia uma complexa relação entre hilotas e espartanos livres. É curioso notar que somente no início do século V a. C., quando não havia alterações na relação entre hilotas e espartanos, as fontes antigas registram duas grandes revoltas: a primeira em 464 a. C. e a outra em 425 a. C. A ausência de revoltas de hilotas no século IV a. C., nesse sentido, serve como indicador de uma revolução social devido a tratamento dispensado a essa categoria social em virtude de sua efetiva participação na sociedade na condição de homem livre.

\section{Notas}

1 - Esse artigo, intitulado Esparta e a sociedade espartana, foi publicado pela primeira vez em 1968 em Problèmes de la guerre en Grèce ancienne organizado por Jean PierreVernant na cidade de Paris pela editora The Hague. Foi também foi publicado em língua portuguesa pela Martins Fontes em São Paulo duas vezes no ano de 1989. Ver FINLEY, M. Economia e sociedade da Grécia antiga e Uso e abuso da história.

2 - Cf. FINLEY, M. Uso e abuso da história, p. 182-6.

3 - Em seu livro Le mirage spartiate: étude sur l'idéalisation de Sparte dans l'antiquité Grecque de l'origene jusqu'aux cyniques, François Ollier analisa as fontes que teceram comentários sobre Esparta, concluindo que houve a repetição de uma tradição a qual idealiza a cidade espartana, construindo uma mirage que influenciou toda a tradição antiga. Sobre esse assunto ver, em especial, os capítulos sobre Xenofonte e Plutarco. 
4 - Sobre o conflito com os hilotas e o seu impacto na sociedade espartana ver Pavel Oliva em seu livro Esparta e sus problemas sociales, Madri, Akal, 1983, p. 40-56.

5 - O exército espartano trazia como símbolo o $\Lambda$ (lambda). A respeito da convivência entre periecos e espartanos ver AUSTIN e VIDAL-NAQUET em Economia e sociedade na Grécia antiga, São Paulo, Martins Fontes (1986) p.90, atribuem a harmonia entre estas duas categorias sociais um dos fatores de estabilidade do regime espartano.

6 - A respeito da disputa interna entre senadores, éforos e reis ver MOSSÉ. Claude, As instituições gregas, Lisboa, Edições 70, 1985, p.104.

7 - A lista com os nomes dos espartanos que prestaram serviços como mercenários elaborada por H. W. PARKER em Greek mercenary soldiers: from the earliest times to the battle of Ipsus demonstra que somente a partir do século IV a. C. houve o desenvolvimento do mercenarismo em Esparta.

8 - Cf. HUXLEY, G. L. Early Sparta. London, Faber and Faber,1962, p.94.

\section{Referências bibliográficas}

BRADFORD, Alfred S. "The duplicitous Spartan”. In: POWELL, Anton \& Hodkinson, Stephen (Orgs.). The shadow of Sparta. London/ New York: The Classical Press of Wales, 1994, p. 59-85.

CARTLEDGE, Paul. Agesilaos and the crisis of Sparta. Baltimore: John Hopkins University Press, 1987.

CAVAIGNAC, Eugène. Sparte. Paris, Fayard, 1948.

CHRIMES, K. M. T. Ancient Sparta: a re-examination of the evidence. Manchester: University Press, 1949.

DUCAT, Jean. Cléomène III et les hilotes. Ktèma, n. 12, p. 43-52, 1987.

. "Les hilotes". In: Bulletin de Correspondence Hellénique. Supplément XX., p. 01208, 1990.

HAMILTON, Charles D. "Social tensions in classical Sparta”. In: Ktéma, n 12, p. 31-41, 1987.

MICHELL, H. Sparta. Cambridge: University Press, 1952.

POWELL, Anton. Athens and Sparta: constructing Greek political and social history from 478 B. C. London/ New York: Routledge, 1996.

TODD, S. C. Athens and Sparta. Great Britain, Bristol Classical Press, 1996.

WALLACE, W.P. "Kleomenes, Maraton, the helots, and Arkadia”. In: JHS, vol. LXXIV, p. $32-35,1954 / 5$. 
SILVA, Maria Aparecida de Oliveira. Helotism and social revolution in Sparta. Classica, São Paulo, 11/12, 265-270 1998/1999.

ABSTRACT: For two centuries the conquest of Messene represented the solution of agrarian, political and economic problems in Sparta. Nevertheless, the internal contradictions of that society contributed to the rupture of the citizens' hegemony in the army of Sparta. The helots had to join the Spartan army as a result of oligantropy in spite of the rupture caused in the system. The aim of this article is to discuss the social revolution provoked in Sparta due to the helots in its army.

KEY-WORDS: Sparta; helots; oligantropy. 